\title{
Effect of aromatherapy massage on anxiety, depression, and physiologic parameters in older patients with the acute coronary syndrome: A randomized clinical trial
}

\section{Authors: Nahid Rejeh Tahereh, Majideh Heravi- Karimooi, Mojtaba Vaismoradi, Seyed Davood, and Christina Sieloff}

This is the peer reviewed version of the following article: see citation below, which has been published in International Journal of Nursing Practice and can be found in final form at https:// dx.doi.org/10.1111/ijn.12601. This article may be used for non-commercial purposes in accordance with Wiley Terms and Conditions for Self-Archiving.

Bahrami, Tahereh, Nahid Rejeh, Majideh Heravi-Karimooi, Mojtaba Vaismoradi, Seyed Davood, and Christina Sieloff. "Effect of aromatherapy massage on anxiety, depression, and physiologic parameters in older patients with the acute coronary syndrome: A randomized clinical trial." International Journal of Nursing Practice (October 2017). DOI: 10.1111/ijn.12601.

Made available through Montana State University's $\underline{\text { ScholarWorks }}$ scholarworks. montana.edu 


\title{
Effect of aromatherapy massage on anxiety, depression, and physiologic parameters in older patients with the acute coronary syndrome: A randomized clinical trial
}

\author{
Tahereh Bahrami ${ }^{1}$, Nahid Rejeh PhD $^{2}$, Majideh Heravi- Karimooi ${ }^{2}$, Mojtaba Vaismoradi ${ }^{3}$, Seyed \\ Davood Tadrisi ${ }^{4}$, and Christina Sieloff ${ }^{5}$ \\ ${ }^{1}$ Department of Nursing, Faculty of Nursing \\ and Midwifery, Shahed University, Tehran, \\ Iran \\ ${ }^{2}$ Elderly Care Research Center, Department of \\ Nursing, Faculty of Nursing and Midwifery, \\ Shahed University, Tehran, Iran \\ ${ }^{3}$ Faculty of Nursing and Health Sciences, Nord \\ University, Bodø, Norway \\ ${ }^{4}$ Faculty of Nursing, Baqiyatallah University of \\ Medical Sciences, Tehran, Iran \\ ${ }^{5}$ College of Nursing, Montana State \\ University, Bozeman, Montana, USA
}

\begin{abstract}
Purpose: This study aimed to investigate the effect of aromatherapy massage on anxiety, depression, and physiologic parameters in older patients with acute coronary syndrome.

Methods: This randomized controlled trial was conducted on 90 older women with acute coronary syndrome. The participants were randomly assigned into the intervention and control groups $(n=45)$. The intervention group received reflexology with lavender essential oil, but the control group only received routine care. Physiologic parameters, the levels of anxiety and depression in the hospital were evaluated using a checklist and the Hospital's Anxiety and Depression Scale, respectively, before and immediately after the intervention.

Results: Significant differences in the levels of anxiety and depression were reported between the groups after the intervention. The analysis of physiological parameters revealed a statistically significant reduction $(P<.05)$ in systolic blood pressure, diastolic blood pressure, mean arterial pressure, and heart rate. However, no significant difference was observed in the respiratory rate. Conclusions: Aromatherapy massage can be considered by clinical nurses an efficient therapy for alleviating psychological and physiological responses among older women suffering from acute coronary syndrome.
\end{abstract}

KEYWORDS

acute coronary syndrome, anxiety, depression, physiologic parameters 


\section{SUMMARY STATEMENT}

What is already known about the topic?

- Depression and anxiety in cardiac care units are often not managed adequately.

- Older adults with acute coronary syndrome may suffer from negative emotions more than other age groups.

What this paper adds?

- This study showed the positive effect of aromatherapy massage on alleviating anxiety and depression among older women with acute coronary syndrome.

- Aromatherapy massage can be considered a complementary therapy and used along with routine interventions for relieving psychological and physiological problems among older women hospitalized in cardiac care units.

The implications of this paper:

- This randomized controlled prospective study provides evidence to support the use of aromatherapy massage with this patient group.

- Aromatherapy massage can be integrated into older patient care for alleviating psychological and physiological responses in women patients who are suffering from acute coronary syndrome.

\section{1 | INTRODUCTION}

Acute coronary syndrome (ACS) is the type of ischaemic heart disease in which coronary arteries are obstructed or closed (Govindaraju, Badruddin, Viswanathan, Ramesh, \& Badarudin, 2013). The ACS leads to the reduction of the oxygen supply to heart muscles because of atherosclerosis or coronary artery spasm. Therefore, an increase in the myocardial oxygen demand, in cases of tachycardia or severe anaemia, enhances the vascular injury and finally may lead to ACS (Cho, Min, Hur, \& Lee, 2013).

As a major public health issue in developing countries, ACS has become highly prevalent, responsible for about $35 \%$ of all deaths across the world. In other words, almost 1 million deaths occur each year because of ACS. Accordingly, about $40 \%$ of ACS-related deaths occur in high-income countries with a share of $28 \%$ in low- to middle-income countries (McKinley et al., 2009; Mohammadpour, Mohammadian, Moghadam, \& Nematollahi, 2014). The ACS is one of the leading causes of hospitalization in the cardiac care unit (CCU) (Han \& Park, 2002). Poor functional statues in the activities of daily livings among patients with ACS result in anxiety and depression (Bauer et al., 2012).

Anxiety affects the function of the body's organs and also causes negative health-related consequences in patients with myocardial infarction (MI) (Huffman et al., 2011). Moreover, the progression of cardiac ischaemia and even dysrhythmia are the significant negative consequences of anxiety and depression (Huffman, Celano, \& Januzzi, 2010). More than half of these patients report the symptoms of anxiety because of the (1) unfamiliar hospitalization's environment, (2) sudden diagnosis of ACS, (3) isolation from the family, (4) being encountered with strangers, (5) loss of individuality and independence, (6) unexpected care routines, and (7) critical situations (McKinley et al., 2012). In addition, these patients encounter many fearful situations such as (1) life-threatening conditions, (2) the probability of an additional MI, and (3) the fear of the unknowns (Arora, Anand, Katyal, \& Anand, 2010). Such discomforts accelerate the release of catecholamine and cause physiologic responses such as an increase in the blood pressure (BP), heart rate (HR), respiratory rate (RR), and dyspnoea, possibly exacerbating the development of MI (Frasure-Smith \& Lesperance, 2008).

The use of medication to relieve anxiety and depression in patients with ACS reduces the level of patients' alertness and may cause further health-related complications (de Jong-Watt \& Arthur, 2004). Therefore, choosing an appropriate method for alleviating patients' anxiety and depression without the use of drugs is of great importance (Rejeh, Heravi-Karimooi, Taheri Kharame, Montazeri, \& Vahedian, 2015).

Currently, more attention is paid to complementary and alternative medicine (CAM) strategies, because they have fewer complications and are easy to access (Mohammadpour et al., 2014). These strategies are highly recommended in older patients with an impaired metabolism and increased sensitivity to the side effects of drugs (Perković-Vukčević, Vuković-Ercegović, Šegrt, Đorđević, \& JovićStošić, 2016). For instance, cognitive and cardiovascular adverse effects among older people, after the use of tranquillisers and cardiovascular drugs, are very common (Sztramko, Chau, \& Wong, 2011). The CAM can help healthcare providers with the management of signs and symptoms related to cardiovascular disorders including ACS (Greenfield, Pattison, \& Jolly, 2008).

Aromatherapy is one of the recommended nonpharmacological CAM strategies for symptom management in hospitalized patients. It is the most widely used complementary therapy in nursing practice and is the therapeutic use of essential oils extracted from plants and administered through the olfactory system (inhalation) or the skin (massage) (Buckle, 2001; Kyle, 2006).

A number of essential oils (lavender, geranium, jasmine, rosemary, rose, evening primrose oil, and chamomile) are used for relieving psychological symptoms such as anxiety and depression (Taavoni, Darsareh, Joolaee, \& Haghani, 2013). Lavender has particularly been used for a long time in traditional medicine with an effect on the central nervous system leading to the release of encephalin, serotonin, and endorphins (Heidari Gorji et al., 2015). Lavender (Lavandula angustifolia) is widely used in different contexts (Hashemi, Hajbagheri, \& Aghajani, 2015). Previous studies have confirmed the sedative effects of Lavender on the parasympathetic system. Also, it has been found that lavender promotes the heart function and coronary blood flow (Bikmoradi et al., 2015). Several studies suggested that aromatherapy and massage had positive effects on physiologic parameter and the level of anxiety and depression (Chang, 2008; Edge, 2003; Hur et al., 2007). Moreover, the risk of hospitalization in the CCU among older patients is more than other groups of patients (Ancona et al., 2004).

Therefore, the aim of this study was to investigate the effect of aromatherapy massage on anxiety, depression, and physiological parameters in older patients with ACS. The research hypothesis for this study was as follows: An aromatherapy massage intervention for older patients with ACS will result in significant differences between an intervention group and control group in terms of anxiety, depression, systolic blood pressure (SBP), diastolic blood pressure (DBP), mean arterial pressure (MAP), HR, and RR. 


\section{I MATERIALS AND METHODS}

\section{1 | Aims}

The aim of this study was to identify the effect of aromatherapy massage on anxiety, depression, and physiologic parameters in older patients with ACS.

\section{2 | Design}

This was a randomized controlled trial with a preintervention-postintervention design. A convenience sample of 90 older patients was randomly allocated into either the intervention or the control group. They were hospitalized for 1 day in the CCU and diagnosed with ACS. The patients in the intervention group received aromatherapy massage with lavender; those in the control group only received routine care delivered by nurses in the CCU.

\subsection{Setting and participants}

This study was conducted in a high turnover CCU of a teaching hospital in Tehran, Iran from July 2014 to December 2015.

Ninety older women, aged 60 years and over, were chosen using a convenience sampling method. None of the participants were excluded from the study. As a result, all of them were randomized into either the intervention or the control groups ( $n=45$ in each group).

The following inclusion criteria were considered for the recruitment of the participants: (1) diagnosed with ACS; (2) 60 years old and above (the beginning of the old age in developing countries); (3) able to understand and communicate in Farsi language and follow instructions; (4) not taking any anxiolytics and sedative drugs during the last 4 hours before the intervention; (5) not receiving alternative and complementary medicines during the last 48 hours before the intervention; (6) not having foot ulcers; (7) no history of drug addiction; (8) no history of asthma, eczema, and allergy; and (9) passing the olfactory heath test and the abbreviated mental test (AMT) (score $\geq 7$ ).

Only female patients with ACS were recruited for this study to eliminate any gender influence on the level of anxiety or depression. The exclusion criteria were as follows: (1) any haemodynamic instability during the intervention; (2) refusing to complete the intervention session; and (3) any allergic reaction to the essential oils or perfumes. It was noted that no harm or side effects occurred throughout the trial.

\section{4 | Sample size}

The sample size was determined using a statistical power analysis ( $\alpha=0.05, \beta=15 \%$, power $=90 \%$, Altman's Nomogram). It was also based on a sample size determined in a previous study (Mahmoudirad, Ghaedi Mosolo \& Bahrami, 2014).

\section{5 | Randomization}

Following receiving the ethical committee's approval at the university and obtaining the permission to enter the $\mathrm{CCU}$, the nurse manager in the CCU was informed of the study's purpose and the selection criteria to help with the identification of eligible participants. A convenience sample of older women, meeting the inclusion criteria, was chosen, with no patient declining to participate.

The allocation of the participants to the groups happened during the week that the researcher (TB) visited the hospital. A system of sealed envelopes was used for the random assignment of the eligible participants into the groups with each envelope assigned to a specific group. The sampling process continued until a sufficient number of the participants were recruited into each group (Figure 1). It is noted that the second author (NR) generated the random allocation sequence and the first author (TB) enrolled participants and assigned participants

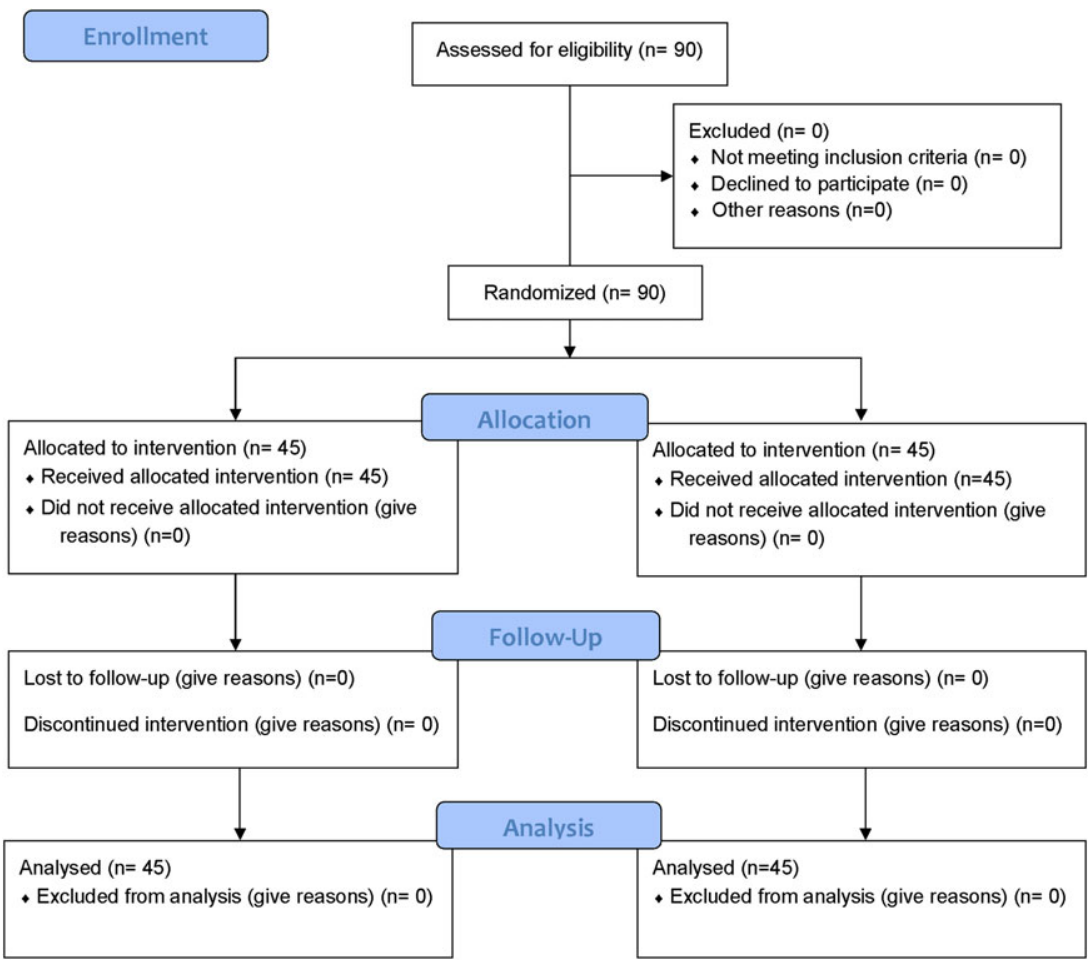


to interventions. It was impossible to control the participants' or staffs' awareness of the group assignment because of the nature of the intervention (aromatherapy massage) and lavender smell. However, the data analyst (SDT) was unaware of the group assignment. In addition, the randomization code was available only to a research fellow who was not connected to this study. The code was disclosed to the researchers when the statistical data analysis was completed.

\section{6 | Measurements}

The instrumentation for this research included several instruments. These included (1) personal and medical information form, (2) measurement of physiological parameters, (3) an AMT, and (4) Hospital Depression and Anxiety Scale (HADS).

\subsubsection{The personal and medical information form}

The personal and medical information form measured demographic characteristics, including (1) age, (2) marital status, (3) employment status, (4) educational level, (5) living status, and (6) any history of hospitalization.

\subsection{2 | Measurement of physiological parameters}

The physiological indicators were measured 1 minute before and after the intervention when the participants were at rest. These parameters included (1) SBP, (2) DBP, (3) MAP, (4) HR, and (5) RR. These data were extracted from participants' charts before and after the intervention. The participants' BP was measured on their left arm using a mercury sphygmomanometer, after they rested for 15 minutes while lying on their back. Instead of a pulse rate, the participants' HR was monitored through the monitoring machine. Also, MAP was measured and reported by this machine. The RR was also measured for 1 minute without the participants being aware of the measurement.

\subsection{3 | Abbreviated mental test}

The AMT rapidly assesses older individuals for the presence of cognitive disorders. Older individuals, with a score greater than 7, were considered normal. A score lower than 7 out of 10 indicated cognitive impairment (Faraji, Fallahi, \& Khankeh, 2013). The Cronbach alpha coefficient of the AMT was reported as 0.76 (Bakhtiyari et al., 2014).

\subsubsection{Hospital anxiety and depression scale}

The HAD scale evaluated the levels of anxiety and depression in the participants. The instrument consisted of 14 items, 7 for each subscale of anxiety (HADS-A) and depression (HADS-D). The participants rated each item on a self-rating scale from 0 to 3 . The scoring system ranged from the absence of symptoms (score 0 ) to the maximal presentation of symptoms (score 3). Therefore, a higher score indicated a higher level of anxiety or depression (Zigmond \& Snaith, 1983). Correlations between the 2 subscales varied from 0.40 to 0.74 with a mean of 0.56 . The Cronbach alpha for the HADS-A varied from 0.68 to 0.93 with a mean of 0.83 , while the alpha for the HADS-D was from 0.67 to 0.90 with a mean 0.82 (Bjelland, Dahl, Haug, \& Neckelmann, 2002). The reliability and validity of the Iranian version of the HADS was assessed (Montazeri et al., 1999). Also, this scale was used in patients with coronary heart diseases in a previous study (Barth \& Martin, 2005). The cut-off score of greater than 8 for the diagnosis of either anxiety or depression was suggested (Stafford, Berk, \& Jackson, 2007). The quantitative scoring of both subscales ranged from 0 to 27 . Scores greater than or equal to 5 were associated with mild anxiety or depression. Scores greater than or equal to 10 were associated with moderate anxiety or depression. Scores greater than or equal to 15 were associated with moderately severe anxiety or depression, while scores equal to or greater than 20 indicated severe anxiety or depression (Kroenke, Spitzer, \& Williams, 2001).

\section{7 | Intervention}

The researcher (TB) explained the study's purpose, benefits, and potential risks to those patients meeting the inclusion criteria. It should be noted that nursing work patterns and nurse staff remained unchanged throughout the study process. During the intervention, the researcher applied the aromatherapy massage to participants exactly as planned. She successfully passed the required training courses with regard to aromatherapy massage under the supervision of specialists in the field of traditional and complementary medicine. The control group received routine care delivered by nurses in the $\mathrm{CCU}$, while the participants who were assigned to the intervention group received the aromatherapy massage intervention in addition to routine care. Routine care was consisted of medication administration based on physicians' orders and scheduled nursing interventions delivered to all patients hospitalized in the CCU.

The intervention was performed in the patient's bed. The nursing staff or family members were asked not to enter when the participant was taking part in the study to minimize noises and disruptions, and enhance relaxation. All participants in the intervention group were placed in a supine position, and a pillow was placed under their knees. The intervention and evaluation of its effect were performed in the evening.

The researcher washed her hands with warm water and applied a moderate amount of almond oil (6 drops) to her hands. After general foot massage, relaxing techniques included effleurage movements (10 times), stretching fingers by holding them between thumbs and other fingers ( 5 times in both directions), and moderate rotational movements around the ankle (5 times). The reflex zones of solar plexus, pituitary gland, brain, heart, large and small intestines, vertebral column, adrenal, and kidney were used for the stimulation. The researcher exerted the firm downward pressure with her thumbs in the above-mentioned areas for (1) 14 seconds in the solar plexus, (2) 40 seconds in the pituitary gland ( 5 times), (3) 5 seconds in the brain area, (4) 10 seconds in heart area, (5) 5 times for each intestine, and (6) 5 times for the adrenal gland and kidney. The rubbing technique was used for the adrenal and kidney reflex zones. Prior to and after the aromatherapy massage intervention, the levels of depression and anxiety in the hospital and physiologic parameters were measured.

\section{8 | Ethical considerations}

The institutional review board approval (decree number: 41-228111) was granted by the university in which the authors worked. All participants signed written informed consent when they were invited to take part in the study. The ethical consideration of this study conformed to the Declaration of Helsinki 1995, revised 2001. Numbers, rather than names, were used to deidentify the participants to ensure their confidentiality and anonymity. Since this intervention used a CAM strategy, 
no harm was anticipated for the participants. However, this study was performed under the supervision and control of a cardiologist in the CCU. No patient withdrew from the study, and no harm was identified as occurring to any participants throughout the study process.

\section{9 | Data analysis}

Statistical analyses were performed using the SPSS version 21.0 software (SPSS Inc., Chicago, Illinois). After the data collection, data analysis was performed using descriptive statistics (frequency, percentage, mean, and standard deviation) and inferential statistics (independent $t$ test, chi-squared test, Cramer $V$ test, and Cohen test). The Kolmogorov-Smirnov test was performed to examine the normal distribution of the data. The level of statistical significance was considered $P<.05$.

\section{3 | RESULTS}

\subsection{The demographic characteristics of the participants at the baseline}

All 90 older women were eligible for inclusion in this study and were approached. All participants agreed to participate and fully completed throughout the study process. The independent $t$ test and chi-square test showed no statistically significant differences between the 2 groups in terms of age, marital status, employment status, educational level, living status, and history of hospitalization (Table 1).

\subsection{Hospital anxiety and depression scale scores}

The statistical analysis with regard to the level of anxiety demonstrated that, after the intervention, the level of anxiety was significantly lower in the intervention group $(\times 2=12.95, \mathrm{df}=3, P=.005)$ as compared with the control group. According to the Cramer $V$ test, the correlation between the intervention and level of anxiety was moderate ( $v 2=0.379$ )

The means and standard deviations of anxiety changed from $12.31 \pm 5.22$ (before the intervention) to $8.04 \pm 4.71$ (after the intervention) in the intervention group, and from $11.66 \pm 4.24$ to $11.07 \pm 3.19$ in the control group. The effect size for the difference in reported anxiety between the groups was 0.75 , demonstrating a large effect size of the aromatherapy massage intervention (Table 2).

In relation to the participants' level of depression, a statistical significant difference between the groups was demonstrated $(\times 2=16.512, \mathrm{df}=3, P=.001)$. Also, the Cramer $\vee$ test revealed a moderate correlation between the aromatherapy massage intervention and the level of depression ( $v 2=0.428$ ). The means and standard deviations for depression changed from $12.51 \pm 5.40$ (before the intervention) to $8.08 \pm 4.71$ (after the intervention) in the intervention group, and from $11.71 \pm 4.29$ to $11.11 \pm 3.42$ in the control group (Table 2).

\section{3 | Physiologic parameters}

The comparison of the physiological parameters for the intervention and control groups was shown in Table 3. There were no statistical

TABLE 1 The demographic characteristics of the participants

\begin{tabular}{|c|c|c|c|c|}
\hline Characteristics & $\begin{array}{l}\text { Total } \\
(\mathrm{n}=90)\end{array}$ & $\begin{array}{l}\text { Intervention } \\
\text { Group } \\
(\mathrm{n}=45)\end{array}$ & $\begin{array}{l}\text { Control } \\
\text { group } \\
(n=45)\end{array}$ & $\begin{array}{l}\text { Statistical test } \\
\text { and } \\
P \text { value }\end{array}$ \\
\hline $\begin{array}{l}\text { Age } \\
\text { Mean } \pm \text { SD }\end{array}$ & $73.300 \pm 7.801$ & $73.97 \pm 7.69$ & $72.62 \pm 7.93$ & $\begin{array}{l}t=-0.823 \\
\mathrm{df}=88 \\
P=.413\end{array}$ \\
\hline \multicolumn{5}{|c|}{ Education level, n (\%) } \\
\hline Illiterate & $66(73.3)$ & $36(45.5)$ & $30(45.5)$ & $x^{2}=2.345$ \\
\hline Diploma & $4(4.4)$ & $1(25)$ & $3(75)$ & $P=.310$ \\
\hline \multicolumn{5}{|c|}{ Marital status, n (\%) } \\
\hline Single & $4(4.4)$ & $3(75)$ & 15(57.7) & $x^{2}=1.682$ \\
\hline Married & $26(28.9)$ & $11(42.3)$ & $1(25)$ & $\mathrm{df}=2$ \\
\hline Widow & $60(66.7)$ & $31(51.7)$ & 29(48.3) & $P=.431$ \\
\hline Disable & 18(20.0) & 10(55.6) & $8(44.4)$ & $P=.827$ \\
\hline \multicolumn{5}{|c|}{ Living status, n (\%) } \\
\hline Alone & $38(42.20$ & $18(47.4)$ & $20(52 / 6)$ & $X^{2}=0.874$ \\
\hline With spouse & $26(28.9)$ & 12(46.2) & $14(53 / 8)$ & $\mathrm{df}=2$ \\
\hline With children & $26(28.9)$ & 15(57.7) & $11(42 / 3)$ & $P=.646$ \\
\hline \multicolumn{5}{|c|}{ History of hospitalization, n (\%) } \\
\hline Yes & $60(66.7)$ & $28(46.7)$ & $32(53.3)$ & Fisher's exact \\
\hline No & $30(33.3)$ & $17(56.7)$ & 13(43.3) & $P=.503$ \\
\hline
\end{tabular}

Note: $P$ values indicated the statistical significance of differences between the intervention and control groups using the independent $t$ test and chi-square test. 
TABLE 2 The comparison of the levels of anxiety and depression before and after the intervention

\begin{tabular}{|c|c|c|c|c|}
\hline Variables & $\begin{array}{l}\text { Intervention } \\
\text { group (n \%) }\end{array}$ & $\begin{array}{l}\text { Control } \\
\text { group (n \%) }\end{array}$ & $\begin{array}{l}\text { Statistical test } \\
\text { and } P \text { value }\end{array}$ & $\begin{array}{l}\text { Cohen } d \\
\text { (Cramer } \\
\left.\mathbf{v}^{2}\right)\end{array}$ \\
\hline \multicolumn{5}{|c|}{ Before the intervention } \\
\hline Normal & $8(17.8)$ & $11(24.4)$ & & \\
\hline Mild & $8(17.8)$ & $11(24.4)$ & $X^{2}=1.808$ & \\
\hline Severe & $16(35.6)$ & 14(31.1) & $P^{a}=0.613$ & \\
\hline $\begin{array}{c}\text { QRS } \\
\text { (Mean } \pm \text { SD) }\end{array}$ & $12.31 \pm 5.22$ & $11.67 \pm 4.24$ & $\begin{array}{l}\text { Leven's test }=0.206 \\
t=-0.642 \\
\mathrm{df}=88 \\
P=.523\end{array}$ & \\
\hline \multicolumn{5}{|l|}{ Depression } \\
\hline Severe & 19(42.2) & 15(33.3) & $P^{a}=0.301$ & \\
\hline $\begin{array}{c}\text { QRS } \\
(\text { Mean } \pm \text { SD) }\end{array}$ & $12.51 \pm 5.40$ & $11.71 \pm 4.29$ & $\begin{array}{l}\text { Leven's test }=0.122 \\
t=-0.778 \\
\mathrm{df}=88 \\
P=.439\end{array}$ & \\
\hline \multicolumn{5}{|c|}{ After the intervention } \\
\hline \multicolumn{5}{|l|}{ Anxiety } \\
\hline Normal & $20(44.4)$ & $5(11.1)$ & & \multirow{3}{*}{$\begin{array}{l}0.75 \\
(0.379)\end{array}$} \\
\hline Mild & $11(24.4)$ & $20(44.4)$ & $X^{2}=12.956$ & \\
\hline Moderate & $9(20.0)$ & $11(24.4)$ & $d f=3$ & \\
\hline Moderate & $8(17.8)$ & $12(26.7)$ & $d f=3$ & \multirow{3}{*}{$\begin{array}{l}0.74 \\
(0.428)\end{array}$} \\
\hline Severe & $4(8.9)$ & $10(22.2)$ & $\mathrm{P}^{\mathrm{a}}=0.001$ & \\
\hline $\begin{array}{l}\quad \text { QRS } \\
\text { (Mean } \pm \text { SD) } \\
\text { Severe }\end{array}$ & $8.04 \pm 4.71$ & $11.11 \pm 3.42$ & $\begin{array}{l}\text { Leven's test }=0.071 \\
t=3.512 \\
\mathrm{df}=88 \\
P=.001\end{array}$ & \\
\hline
\end{tabular}

Note: $P$ values indicated the statistical differences between the groups using chi-squared test for the qualitative rating system of anxiety and depression. $P$ value reported for the quantitative rating system using $t$ test by considering the equality of variances.

Cramer $v^{2}$ showed the correlation between the intervention, anxiety, and depression.

Cohen $d$ represented the effect size of the intervention on anxiety and depression, while considering their qualitative scoring systems. QRS stands for the quantitative rating system.

significant differences between the groups before the intervention except for RR. While SBP, DBP, MBP, and HR significantly reduced after the intervention, no statistically significant difference was found in RR in the intervention group after the intervention. The assessment of the Cohen test demonstrated an average effect size in SBP, DBP, and MBP, but a small effect size in HR (Table 3).

\section{4 | DISCUSSION}

The present study was conducted to investigate the effect of aromatherapy massage on anxiety, depression, and physiological parameters among older women with ACS. After the intervention, aromatherapy massage significantly improved the levels of anxiety and depression and decreased SBP, DBP, MBP, and HR as compared with the baselines. However, despite a clinical decline in RR, no statistically significant reduction was reported.

Psychological issues, caused by an ACS in older people, can have negative impacts on their lives, and these additional problems should be managed by healthcare professionals. Many studies suggested different treatment modalities for the management of anxiety and depression, and the equilibration of physiologic parameters, but an interest in the use of complementary and alternative therapies among 
TABLE 3 The comparison of physiologic parameters before and after the intervention

\begin{tabular}{|c|c|c|c|c|c|c|}
\hline Parameter & Group & $\begin{array}{l}\text { SBP } \\
\text { Mean } \pm S D\end{array}$ & $\begin{array}{l}\text { DBP } \\
\text { Mean } \pm \text { SD }\end{array}$ & $\begin{array}{l}\text { MAP } \\
\text { Mean } \pm S D\end{array}$ & $\begin{array}{l}\text { HR } \\
\text { Mean } \pm S D\end{array}$ & $\begin{array}{l}\text { RR } \\
\text { Mean } \pm \text { SD }\end{array}$ \\
\hline Before intervention & $\begin{array}{l}\text { Control } \\
\text { Intervention }\end{array}$ & $\begin{array}{l}128.42 \pm 18.83 \\
129.51 \pm 11.66\end{array}$ & $\begin{array}{l}76.13 \pm 12.84 \\
80.31 \pm 9.71\end{array}$ & $\begin{array}{l}94.33 \pm 16.34 \\
94.63 \pm 7.94\end{array}$ & $\begin{array}{l}81.24 \pm 11.77 \\
76.53 \pm 11.19\end{array}$ & $\begin{array}{l}14.20 \pm 2.89 \\
18.00 \pm 2.34\end{array}$ \\
\hline Statistical test & & Leven's $=0.002$ & Leven's $=0.278$ & Leven's $=0.000$ & Leven's $=0.961$ & Leven's $=0.405$ \\
\hline$P$ value & & $\begin{array}{l}t=-0.330 \\
\mathrm{df}=73.42 \\
P=.743\end{array}$ & $\begin{array}{l}t=-1.74 \\
\mathrm{df}=88 \\
P=.085\end{array}$ & $\begin{array}{l}t=-0.10 \\
\mathrm{df}=63.71 \\
P=.913\end{array}$ & $\begin{array}{l}t=1.94 \\
\mathrm{df}=88 \\
P=.055\end{array}$ & $\begin{array}{l}t=-6.84 \\
\mathrm{df}=88 \\
P<.001\end{array}$ \\
\hline Statistical test & & Leven's $=0.000$ & Leven's $=0.000$ & Leven's $=0.000$ & Leven's $=0.046$ & Leven's $=0.044$ \\
\hline$P$ value & & $\begin{array}{l}t=2.661 \\
d f=66.44 \\
P=.010\end{array}$ & $\begin{array}{l}t=2.42 \\
d f=67.04 \\
P=.018\end{array}$ & $\begin{array}{l}t=3.06 \\
\mathrm{df}=60.25 \\
P=.003\end{array}$ & $\begin{array}{l}t=2.08 \\
\mathrm{df}=83.33 \\
P=.040\end{array}$ & $\begin{array}{l}t=-3.99 \\
\mathrm{df}=78.95 \\
P<.001\end{array}$ \\
\hline Effect size & & $d=0.65$ & $d=0.54$ & $d=0.78$ & $d=0.41$ & \\
\hline
\end{tabular}

Note: $P<.05$

Data are represented as means \pm standard deviation. $P$ values indicated differences between the groups using the independent $t$ test by considering the equality of variance.

Cohen $d$ represented the effect size of the intervention on physiologic parameters. DBP, diastolic blood pressure; HR, heart rate; MAP, mean arterial pressure; RR, respiratory rate; SBP, systolic blood pressure.

older patients with heart diseases is increasing (Sibbritt, Davidson, DiGiacomo, Newton, \& Adams, 2015). Various studies have confirmed the efficacy of nonpharmacological measures such as aromatherapy massage for relieving psychological symptoms in different groups of patients(Cooke \& Ernst, 2000; Kuriyama et al., 2005; Okamoto et al., 2005), but immediate consequences and benefits of this therapy on the levels of anxiety and depression are still unknown.

In the present study, most participants reported the initial high levels of anxiety and depression. However, after the aromatherapy massage intervention, the participants showed statistically significant reductions in their symptoms as compared with those of the control group. These findings are supported by the findings of previous studies on the use of essential oil massage for relieving similar symptoms (Domingos Tda \& Braga, 2015; Wilkinson, Aldridge, Salmon, Cain, \& Wilson, 1999). In addition, a recent study examined the impact of aromatherapy massage on psychological parameters and found that aromatherapy massage also improved patients' anxiety and depression (Wu et al., 2014).

According to the findings of this study, aromatherapy massage reduced the psychological symptoms of the participants. These reductions might be attributed to the relaxant effects of lavender on the autonomic nervous system with an associated effect on the patient's emotions. Perry and Perry (2006) also emphasized the antianxiety mechanism of the linalool in lavender. Other studies among animals showed that the pharmacologic effect of lavender was similar to that of diazepam (Perry \& Perry, 2006; Umezu, 2000). In addition, according to one hypothesis, the use of essential oils may also help reduce the blockage of the olfactory pathways and lead to antidepressant effects (Hongratanaworakit, 2011; Yim, $\mathrm{Ng}$, Tsang, \& Leung, 2009).

In contrast, Kuriyama et al. (2005) did not report any significant reduction in the anxiety level with a course of aromatherapy or massage (Kuriyama et al., 2005). Soden, Vincent, Craske, Lucas, and Ashley (2004) and Chang (2008) reported a significant reduction in the level of depression after receiving the treatment in patients with cancer, but the treatment had no effect on the level of anxiety (Chang, 2008; Soden et al., 2004). Despite the gradual reduction of anxiety in patients with breast cancer in the study Imanishi et al. (2009), researchers did not find any statistically significant difference in the participants' level of depression (Imanishi et al., 2009; Stevensen, 1994). Several factors including type of patients, underlying disorders, the duration and method of intervention, patient's psychological conditions, or the amount and type of aroma may contribute to the conflicting findings on the effects of lavender on participants' psychological symptoms.

As a complex process, aromatherapy massage consists of aroma oil for the olfactory stimulation, and a massage as a tactile stimulation. This combination therapy may improve participants' physiologic parameters through the absorption of the aroma oil by the skin and subsequent stimulation of the olfactory system. This therapeutic remedy can affect the parasympathetic nervous system, stabilizing the patient's physiologic parameters and metabolism and, eventually, maintaining the patient's level of relaxation (Eguchi et al., 2016; Imura, Misao, \& Ushijima, 2006; Kim \& Kim, 2012).

In this study, changes in BP were seen in those participants with reduced anxiety and depression after the intervention. As other studies also indicated that BP was decreased with the reduction of anxiety, it was believed that aroma foot massage might reduce BP through reducing the participant's anxiety (Eguchi et al., 2016). In addition, other studies also reported the decreased levels of SBP, DBP, and MBP after aroma self-foot reflexology massage (Bahrami, Rejeh, Heravi Karimooi, Tadrisi, \& Amin, 2016; Hur et al., 2007; Kim \& Kim, 2012). In contrast, Rho, Han, Kim, and Lee (2006) stated that aromatherapy massage had no statistically significant differences in BP and HR between the 2 groups (Rho et al., 2006).

Complementary medicine experts believe that during and immediately after the intervention, some changes in the HR, RR, or temperature may be created. Therefore, such interventions should be 
provided in more than one session to be able to assess and document its benefits (Gunnarsdottir \& Jonsdottir, 2010). This phenomenon, known as a cleansing process, can be the reason for the lack of changes in RR in this study. Unlike our findings, Stevenson and Chang believe that RR decrease as an immediate effect of massage with the essential oil (Chang, 2008; Stevensen, 1994). Also Domingos Tda and Braga (2015) stated that the application of a mixture of essential oils through massage in children with first-degree burns made a significant decrease in the HR and RR (Domingos Tda \& Braga, 2015).

This study has several strengths. The researchers evaluated the effects of complementary therapies in older women as a neglected area of research in relation to complementary therapy. This was also the first study to examine the effect of aromatherapy massage in patients with ACS. Furthermore, studies on the biological outcomes following aromatherapy massage have been very limited. This study was conducted in one hospital with a group of homogeneous participants to prevent any threat to the generalization of the findings. However, further studies in other hospitals with a larger sample size from both genders are suggested.

\subsection{Limitations and recommendation for future research of the study}

Although this research demonstrated that aromatherapy massage can have beneficial effects on psychological and physiological symptoms, a lack of long-term massage and follow-up may have limited the full effect of the intervention.

Another challenge was the inability to distinguish the effects of aromatherapy from the effects of massage. However, the researchers hypothesized that a combination of aroma oil and massage might have increased the effectiveness of the intervention. Therefore, future studies focusing on the comparison of massage with and without essential oils are suggested. Also, it is recommended to continue the aromatherapy massage for at least 1 month. Further studies on the application of aromatherapy massage in the $\mathrm{CCU}$ are also proposed to investigate its effect concerning patients' sedation levels and address the abovementioned limitations. Contradictions in physiologic parameters in different studies warrant the necessity of further examination of the effect of aromatherapy massage. On the other hand, if the effectiveness of aromatherapy massage is confirmed in future clinical settings, healthcare providers should consider their use for treatment purposes.

\section{5 | CONCLUSION}

Aromatherapy massage can be considered an efficient therapy for alleviating anxiety, depression, and physiological responses among older women suffering from the ACS. The researchers suggest that this nonpharmacologic intervention can be used by clinical nurses, along with other measures, to relieve patients' physiologic and psychologica responses during the provision of care in the CCU. Adding complementary therapies in healthcare settings, especially the CCU, may provide an alternative for the high use of medications in the ageing population.

\section{ACKNOWLEDGEMENT}

The researchers would like to express their gratitude to the participants for taking part in this study. Shahed University provided financial support for this research project.

\section{CONFLICT OF INTEREST}

None of the authors have any conflicts of interests with regard to this research.

\section{FUNDING}

This research was supported financially by a grant from Shahed University, Tehran, Iran (decree code: P/A/13/93).

\section{CONTRIBUTIONS}

Study design: T.B., N.R. Data collection: T.B., N.R. Data analysis: S.J., S.D.T. Manuscript preparation and critical revision: T.B., N.R., M.V., C.S. Final approval of the version to be published: T.B., N.R., M.H.K., M.V., C.S.

\section{REFERENCES}

Ancona, C., Arca, M., Saitto, C., Agabiti, N., Fusco, D., Tancioni, V., \& Perucci, C. A. (2004). Differences in access to coronary care unit among patients with acute myocardial infarction in Rome: Old, ill, and poor people hold the burden of inefficiency. BMC Health Services Research, 4(1), 34.

Arora, D., Anand, M., Katyal, V., \& Anand, V. (2010). Anxiety and well-being among acute coronary syndrome patients: Overtime. Journal of the Indian Academy of Applied Psychology, 36, 79-88.

Bahrami, T., Rejeh, N., Heravi Karimooi, M., Tadrisi, S. D., \& Amin, G. (2016). Effect of aromatherapy massage on fatigue and hemodynamic parameteres in elderly women with acute coronary syndrome. Journal of Nursing and Midwifery Urmia University of Medical Sciences, 14(4), 343-351.

Bakhtiyari, F., Foroughan, M., Fakhrzadeh, H., Nazari, N., Najafi, B., Alizadeh, M., ... Mostafa, Q. (2014). Validation of the persian version of Abbreviated Mental Test (AMT) in elderly residents of Kahrizak charity foundation. Iranian Journal of Diabetes and Metabolism, 13(6), 487-494.

Barth, J., \& Martin, C. R. (2005). Factor structure of the Hospital Anxiety and Depression Scale (HADS) in German coronary heart disease patients. Health and Quality of Life Outcomes, 3(1), 1-9.

Bauer, L. K., Caro, M. A., Beach, S. R., Mastromauro, C. A., Lenihan, E., Januzzi, J. L., \& Huffman, J. C. (2012). Effects of depression and anxiety improvement on adherence to medication and health behaviors in recently hospitalized cardiac patients. American Journal of Cardiology, 109(9), 1266-1271.

Bikmoradi, A., Seifi, Z., Poorolajal, J., Araghchian, M., Safiaryan, R., \& Oshvandi, K. (2015). Effect of inhalation aromatherapy with lavender essential oil on stress and vital signs in patients undergoing coronary artery bypass surgery: A single-blinded randomized clinical trial. Complementary Therapies in Medicine, 23(3), 331-338. 
Bjelland, I., Dahl, A. A., Haug, T. T., \& Neckelmann, D. (2002). The validity of the Hospital Anxiety and Depression Scale: An updated literature review. Journal of Psychosomatic Research, 52(2), 69-77.

Buckle, J. (2001). The role of aromatherapy in nursing care. Nursing Clinics of North America, 36(1), 57-72.

Chang, S. Y. (2008). Effects of aroma hand massage on pain, state anxiety and depression in hospice patients with terminal cancer. Taehan Kanho Hakhoe Chi, 38(4), 493-502.

Cho, M. Y., Min, E. S., Hur, M. H., \& Lee, M. S. (2013). Effects of aromatherapy on the anxiety, vital signs, and sleep quality of percutaneous coronary intervention patients in intensive care units. Evidence-based Complementary and Alternative Medicine, 2013, 381381.

Cooke, B., \& Ernst, E. (2000). Aromatherapy: A systematic review. British Journal of General Practice, 50(455), 493-496.

de Jong-Watt, W. J., \& Arthur, H. M. (2004). Anxiety and health-related quality of life in patients awaiting elective coronary angiography. Heart \& Lung: The Journal of Acute and Critical Care, 33(4), 237-248.

Domingos Tda, S., \& Braga, E. M. (2015). Massage with aromatherapy: Effectiveness on anxiety of users with personality disorders in psychiatric hospitalization. Revista da Escola de Enfermagem da USP, 49(3), 453-459.

Edge, J. (2003). A pilot study addressing the effect of aromatherapy massage on mood, anxiety and relaxation in adult mental health. Complementary Therapies in Nursing \& Midwifery, 9(2), 90-97.

Eguchi, E., Funakubo, N., Tomooka, K., Ohira, T., Ogino, K., \& TanigawaT (2016). The effects of aroma foot massage on blood pressure and anxiety in Japanese community-dwelling men and women: A crossover randomized controlled trial. PLoS One, 11(3), e0151712.

Faraji, J., Fallahi, K. M., \& Khankeh, H. (2013). The effect of poetry therapy on the cognitive status in elderly residents of a nursing home. Complementary Medicine Journal, 2(4), 312-323.

Frasure-Smith, N., \& Lesperance, F. (2008). Depression and anxiety as predictors of 2-year cardiac events in patients with stable coronary artery disease. Archives of General Psychiatry, 65(1), 62-71.

Govindaraju, K., Badruddin, I. A., Viswanathan, G. N., Ramesh, S. V., \& Badarudin, A. (2013). Evaluation of functional severity of coronary artery disease and fluid dynamics' influence on hemodynamic parameters: A review. European Journal of Medical Physics, 29(3), 225-232.

Greenfield, S., Pattison, H., \& Jolly, K. (2008). Use of complementary and alternative medicine and self-tests by coronary heart disease patients. BMC Complementary and Alternative Medicine, 8, 47.

Gunnarsdottir, T. J., \& Jonsdottir, H. (2010). Healing crisis in reflexology: Becoming worse before becoming better. Complementary Therapies in Clinical Practice, 16(4), 239-243.

Han, K. S., \& Park, Y. I. (2002). The level of anxiety and relating factors of ICU patients. The Journal of Korean Academic Society of Nursing Education, 8(1), 155-166.

Hashemi, S. H., Hajbagheri, A., \& Aghajani, M. (2015). The effect of massage with lavender oil on restless leg syndrome in hemodialysis patients: A randomized controlled trial. Nursing and Midwifery Studies, 4(4), e29617.

Heidari Gorji, M. A., Ashrastaghi, O. G., Habibi, V., Charati, J. Y., Ebrahimzadeh, M. A., \& Ayasi, M. (2015). The effectiveness of lavender essence on strernotomy related pain intensity after coronary artery bypass grafting. Advanced Biomedical Research, 4, 127.

Hongratanaworakit, T. (2011). Aroma-therapeutic effects of massage blended essential oils on humans. Natural product communications Journal, 6(8), 1199-1204.

Huffman, J. C., Celano, C. M., \& Januzzi, J. L. (2010). The relationship between depression, anxiety, and cardiovascular outcomes in patients with acute coronary syndromes. Neuropsychiatric Disease and Treatment, 6(123-36), 11.

Huffman, J. C., Mastromauro, C. A., Sowden, G., Fricchione, G. L., Healy, B. C., \& Januzzi, J. L. (2011). Impact of a depression care management program for hospitalized cardiac patients. Circulation. Cardiovascular Quality and Outcomes, 4(2), 198-205.
Hur, M. H., Oh, H., Lee, M. S., Kim, C., Choi, A. N., \& Shin, G. R. (2007) Effects of aromatherapy massage on blood pressure and lipid profile in Korean climacteric women. International Journal of Neuroscience, 117(9), 1281-1287.

Imanishi, J., Kuriyama, H., Shigemori, I., Watanabe, S., Aihara, Y., Kita, M., ... Kunisawa, M. (2009). Anxiolytic effect of aromatherapy massage in patients with breast cancer. Evidence-based Complementary and Alternative Medicine, 6(1), 123-128.

Imura, M., Misao, H., \& Ushijima, H. (2006). The psychological effects of aromatherapy-massage in healthy postpartum mothers. Journal of Midwifery \& Women's Health, 51(2), e21-e27.

Kim, J. O., \& Kim, I. S. (2012). Effects of aroma self-foot reflexology massage on stress and immune responses and fatigue in middle-aged women in rural areas. Journal of Korean Academy of Nursing, 42(5), 709-718.

Kroenke, K., Spitzer, R. L., \& Williams, J. B. (2001). The PHQ-9: Validity of a brief depression severity measure. Journal of General Internal Medicine, 16(9), 606-613.

Kuriyama, H., Watanabe, S., Nakaya, T., Shigemori, I., Kita, M., Yoshida, N., ... Imanishi, J. (2005). Immunological and psychological benefits of aromatherapy massage. Evidence-based Complementary and Alternative Medicine, 2(2), 179-184.

Kyle, G. (2006). Evaluating the effectiveness of aromatherapy in reducing levels of anxiety in palliative care patients: results of a pilot study. Complementary Therapies in Clinical Practice, 12(2), 148-155.

Mahmoudirad, G., Ghaedi Mosolo, M., Bahrami, H. (2014). Effect of foot reflexology on anxiety of patients undergoing coronary angiography. International Journal of Computing, Communications and Networking, 6(4), 235-242.

McKinley, S., Dracup, K., Moser, D. K., Riegel, B., Doering, L. V., Meischke, H., ... Pelter, M. (2009). The effect of a short one-on-one nursing intervention on knowledge, attitudes and beliefs related to response to acute coronary syndrome in people with coronary heart disease: A randomized controlled trial. International Journal of Nursing Studies, 46(8), 1037-1046.

McKinley, S., Fien, M., Riegel, B., Meischke, H., Aburuz, M. E., Lennie, T. A., \& Moser, D. K. (2012). Complications after acute coronary syndrome are reduced by perceived control of cardiac illness. Journal of Advanced Nursing, 68(10), 2320-2330.

Mohammadpour, A., Mohammadian, B., Moghadam, M. B., \& Nematollahi, M. R. (2014). The effect of local heat therapy on physiologic parameters of patients with acute coronary syndrome: a randomized controlled clinical trial. Journal of Critical Care Nursing, 7(2), 74-83.

Montazeri, A., Harirchi, I., Vahdani, M., Khaleghi, F., Jarvandi, S., Ebrahimi, M., \& Haji-Mahmoodi, M. (1999). The European Organization for Research and Treatment of Cancer Quality of Life Questionnaire (EORTC QLQ-C30): Translation and validation study of the Iranian version. Support Care Cancer, 7(6), 400-406.

Okamoto, A., Kuriyama, H., Watanabe, S., Aihara, Y., Tadai, T., Imanishi, J., \& Fukui, K. (2005). The effect of aromatherapy massage on mild depression: A pilot study. Psychiatry and Clinical Neurosciences, 59(3), 363-363.

Perković-Vukčević, N., Vuković-Ercegović, G., Šegrt, Z., Đorđević, S., \& Jović-Stošić, J. (2016). Benzodiazepine poisoning in elderly. Vojnosanitetski Pregled, 73(3), 234-238.

Perry, N., \& Perry, E. (2006). Aromatherapy in the management of psychiatric disorders. CNS Drugs, 20(4), 257-280.

Rejeh, N., Heravi-Karimooi, M., Taheri Kharame, Z., Montazeri, A., \& Vahedian, A. (2015). Quality of life in patients with myocardial infarction and related factors: A cross sectional Study. Iranian Journal of Nursing Research, 9(4), 1-11.

Rho, K. H., Han, S. H., Kim, K. S., \& Lee, M. S. (2006). Effects of aromatherapy massage on anxiety and self-esteem in Korean elderly women: A pilot study. International Journal of Neuroscience, 116(12), 1447-1455.

Sibbritt, D., Davidson, P., DiGiacomo, M., Newton, P., \& Adams, J. (2015). Use of complementary and alternative medicine in women with heart 
disease, hypertension and diabetes (from the Australian longitudinal study on Women's health). The American Journal of Cardiology, 115(12), 1691-1695.

Soden, K., Vincent, K., Craske, S., Lucas, C., \& Ashley, S. (2004). A randomized controlled trial of aromatherapy massage in a hospice setting. Palliative Medicine, 18(2), 87-92.

Stafford, L., Berk, M., \& Jackson, H. J. (2007). Validity of the Hospital Anxiety and Depression Scale and Patient Health Questionnaire-9 to screen for depression in patients with coronary artery disease. General Hospital Psychiatry - Journal, 29(5), 417-424.

Stevensen, C. (1994). The psychophysiological effects of aromatherapy massage following cardiac surgery. Complementary Therapies in Medicine, 2(1), 27-35.

Sztramko, R., Chau, V., \& Wong, R. (2011). Adverse drug events and associated factors in heart failure therapy among the very elderly. Canadian Geriatrics Journal, 14(4), 79-92.

Taavoni, S., Darsareh, F., Joolaee, S., \& Haghani, H. (2013). The effect of aromatherapy massage on the psychological symptoms of postmenopausal Iranian women. Complementary Therapies in Medicine, 21(3), 158-163.

Umezu, T. (2000). Behavioral effects of plant-derived essential oils in the geller type conflict test in mice. The Japanese Journal of Pharmacology, 83(2), 150-153.
Wilkinson, S., Aldridge, J., Salmon, I., Cain, E., \& Wilson, B. (1999). An evaluation of aromatherapy massage in palliative care. Palliative Medicine, 13(5), 409-417.

Wu, J. J., Cui, Y., Yang, Y. S., Kang, M. S., Jung, S. C., Park, H. K., ... Eun, S. Y. (2014). Modulatory effects of aromatherapy massage intervention on electroencephalogram, psychological assessments, salivary cortisol and plasma brain-derived neurotrophic factor. Complementary Therapies in Medicine, 22(3), 456-462.

Yim, V. W., Ng, A. K., Tsang, H. W., \& Leung, A. Y. (2009). A review on the effects of aromatherapy for patients with depressive symptoms. Journal of Alternative and Complementary Medicine, 15(2), 187-195.

Zigmond, A., \& Snaith, R. (1983). The hospital anxiety and depression scale. Acta Psychiatrica Scandinavica, 67(6), 361-370.

How to cite this article: Bahrami T, Rejeh N, Heravi- Karimooi M, Vaismoradi M, Tadrisi SD, Sieloff C. Effect of aromatherapy massage on anxiety, depression, and physiologic parameters in older patients with the acute coronary syndrome: A randomized clinical trial. Int J Nurs Pract. 2017;23:e12601. https:// doi.org/10.1111/ijn.12601 